\title{
ENSAIO COM BASE EM ESTUDOS PUBLICADOS SOBRE OS SABERES CONSTITUINTES DA PROFISSIONALIDADE DO PROFESSOR DE BEBÊS
}

\section{TEST BASED ON PUBLISHED STUDIES ON KNOWLEDGE CONSTITUIENTES BABIES TEACHER PROFESSIONALISM}

\author{
SILVA, José Ricardo \\ ricardo.unesp@hotmail.com \\ FCT UNESP - Faculdade de Ciências e Tecnologias \\ CACHEFFO, Viviane Aparecida Ferreira Favareto \\ vivianecacheffo@gmail.com \\ FCT UNESP - Faculdade de Ciências e Tecnologias \\ GUIMARÃES, Célia Maria \\ celiamguimaraes@terra.com.br \\ FCT UNESP - Faculdade de Ciências e Tecnologias
}

RESUMO $O$ objetivo deste ensaio é identificar, por meio do mapeamento bibliográfico de pesquisas nacionais, os saberes apontados como constituintes da profissionalidade de professores que atuam com bebês. Como base de dados, optou-se pelo banco de teses e dissertações das Universidades públicas do Estado de São Paulo e os artigos publicados nas reuniões anuais da Associação Nacional de Pós-Graduação e Pesquisa em Educação - ANPed - entre 2000 e 2013. Constatamos que os saberes constituintes da profissionalidade dos professores de bebês abarcam a compreensão do bebê como centro do planejamento das práticas educativas e, para isso, o fazer docente envolve conhecimentos científicos, filosóficos, sociológicos que precisam ser lançados de forma a orientar tal relação.

PALAVRAS-CHAVE: Educação Infantil. Professor de Bebês. Profissionalidade. Saberes.

\section{ABSTRACT}

The goal is to identify, through bibliographic mapping of national research, knowledge identified as professionalism constituents of teachers who work with babies. As database, we opted for the bank theses and dissertations public universities of São Paulo, and the annual meetings and the articles published in the annual meetings of the National Association of Graduate Studies and Research in Education - Anped between 2000 and 2013. We found that the professionalism of the constituents of knowledge babies teachers cover understanding the baby as the center of planning of educational practices and, therefore, the teaching involves making scientific knowledge, philosophical, sociological that need to be launched in order to guide this relationship.

KEYWORDS: Childhood Education. Professor Babies. Professionalism. Knowledge. 


\section{INTRODUÇÃO}

O presente estudo visa a identificar, por meio do mapeamento bibliográfico, quais são os saberes apontados por pesquisas nacionais como constituintes da profissionalidade da professora ${ }^{1}$ de creche. Originou-se com o intuito de revelar o que as pesquisas acadêmicas estão sinalizando como saberes necessários para a atuação do professor de bebês ${ }^{2}$, inquietação suscitada pela participação na disciplina "Formação de Professores para Educação Infantil: Processos e Desafios da Profissionalidade", do Programa de Pós-Graduação em Educação, na modalidade de Doutorado.

Como base de dados para esta investigação, optamos pelos trabalhos apresentados nas reuniões anuais da Associação Nacional de Pós-Graduação e Pesquisa em Educação (ANPed), mais especificamente nos grupos de trabalho que se relacionam com a faixa etária pesquisada, a saber: Grupo de Trabalho "Educação de crianças de 0 a 6 anos" (GT 07) e Grupo de Trabalho "Formação de Professores" (GT 08), publicados no período entre 2000 e 2013, e no banco de teses e dissertações de programas de Educação das Universidades públicas do Estado de São Paulo ${ }^{3}$ (USP, UNESP e UNICAMP), no mesmo período. Os descritores utilizados na investigação foram: educação infantil, bebês, berçário, maternal, recém-nascido, creche, crianças pequenas de 0 a 3 anos, o que nos possibilitou a localização, leitura, categorização e análise de 25 estudos, sendo 18 artigos provenientes da ANPed, 7 dissertações e 3 teses que revelaram saberes constituintes da profissionalidade dos professores de bebês, mesmo quando este não fora o objetivo principal dos respectivos trabalhos.

Em relação ao conceito de profissionalidade, Sacristán (1991, p. 65) salienta que pode ser definido como o "[...] que é específico na ação docente, isto é, o conjunto de comportamentos, conhecimentos, destrezas, atitudes e valores que

\footnotetext{
${ }^{1}$ A terminologia professora é utilizada com respaldo na LDB no 9.394/96 e está no feminino, por ser expressiva a porcentagem de mulheres, nesse segmento educacional (GATTI, 1997).

${ }^{2}$ Neste texto, consideramos bebês as crianças de até 18 meses de idade, dotadas "[...] de um corpo no qual afeto, intelecto e motricidade estão profundamente conectados, e é a forma particular como esses elementos se articulam que vai definindo as singularidades de cada indivíduo ao longo de sua história" (BARBOSA, 2010, p. 02).

${ }_{3}$ Por tratar-se de um ensaio, escolhemos apenas o banco de dados de três universidades estaduais paulistas.
} 
constituem a especificidade de ser professor". Concordamos com Roldão (2005), para quem sua ocorrência se manifesta quando há

[...] o reconhecimento social da especificidade da função associada à actividade (por oposição à indiferenciação); 0 saber específico indispensável ao desenvolvimento da actividade e sua natureza; o poder de decisão sobre a acção desenvolvida e consequente responsabilização social e pública pela mesma - dito doutro modo, o controlo e sobre a actividade e a autonomia do seu exercício; e a pertença a um corpo colectivo que partilha, regula e defende, intra-muros desse colectivo, quer o exercício da função e o acesso a ela, quer a definição do saber necessário, quer naturalmente 0 seu poder sobre a mesma que lhe advém essencialmente do reconhecimento de um saber que o legitima (ROLDÃO, 2005, p. 109).

Portanto, nossa preocupação nesta investigação reside no fato de que, aparentemente, a atuação do professor de bebês tem-se caracterizado como de maternagem, a qual apenas executa tarefas de uma mãe, que se assemelham com afazeres domésticos, sem a devida reflexão teórica e/ou científica acerca de sua função no trabalho.

Sabemos que essa característica não está alheia à história da Educação Infantil brasileira. É nítida, até mesmo aos olhos de observadores comuns, a precariedade da educação pública. Tais obstáculos persistem e marcam seu avanço - nos âmbitos legais, estruturais, de formação de professores (inicial, continuada e em serviço), entre outros. Ao longo do tempo, diversas pesquisas denunciaram tais problemas, tais como as realizadas por Campos (2009), Nosela (2002), Kramer (2002), Santos (2005), Kulhmann (2005, 2007), Cerisara (2010a, 2010b) e Sayão (2010).

Contudo, alguns desses problemas ainda não foram superados, haja vista que resquícios históricos influenciam as práticas docentes, de modo a desqualificálas e reforçar estigmas históricos. Não podemos, também, ignorar o fato de que não há formação específica para professora de Educação Infantil. De acordo com Lüdke e Boing (2004), a formação dessas profissionais tem sido realizada por diferentes instituições e até mesmo em diferentes níveis de ensino, por exemplo, cursos oferecidos pelas universidades, como os de Pedagogia, Curso Normal Superior, dentro dos institutos superiores de educação e, ainda, o antigo Curso Normal ou Magistério.

Tais limitações foram detectadas nos diferentes níveis da Educação Infantil. Embora haja, atualmente, avanços teóricos e práticos que nos auxiliam na 
caracterização dos saberes constituintes da profissionalidade da educadora infantil, notamos que esse desarranjo se torna ainda mais preocupante no que concerne ao atendimento de bebês nas creches. Esse nível de ensino ainda enfrenta uma desvalorização social da profissão, com isso, a procura para exercê-la é baixa, por não demonstrar-se como um campo promissor de trabalho.

Consequentemente, há um desajuste, uma crise de identidade em relação às professoras de creche. Por um lado, concepções errôneas do imaginário social quanto ao trabalho educativo realizado pelas professoras nas creches que, por vezes, acabam por influenciar as práticas docentes e prejudicam a constituição dos saberes necessários para o exercício da profissão (ÁVILA, 2002; CUNHA; CARVALHO, 2002; COTA, 2007). Por outro lado, tem-se a compreensão, de pessoas envolvidas com a Educação Infantil, de que as responsáveis pelo cuidado/educação de bebês nas creches não precisam ter formação específica, bastando ser mulher e mãe, gostar de crianças, "ter jeito", para desempenhar a função. Com isso, instala-se no trabalho institucionalizado com bebês uma tendência denominada por Martins (2009) como "pedagogia da espera".

Essa tendência decorre de uma incoerente percepção do próprio professor acerca de seu trabalho no berçário, quando entende que não há nada a ser feito com os bebês, além de prover suas necessidades fisiológicas de alimentação, higiene e sono. Caracteriza-se, dessa forma, a rotina da instituição como afazeres domésticos, focados na proteção, alimentação e higiene; o trabalho docente como não diretivo, espontâneo, embasado no cotidiano, no empirismo, no conhecimento tácito e na espera pelo desenvolvimento do bebê que há de vir e que, por isso, não há trabalho pedagógico a ser realizado com ele.

Entretanto, Barbosa (2010, p. 6) sinaliza que "[...] a profissão de professora na creche não é, como muitos acreditam, apenas a continuidade dos afazeres 'maternos', mas uma construção de profissionalização que exige bem mais que competência teórica, metodológica e relacional".

No entanto, reconhecemos a importância de que o bebê seja considerado para além dos aspectos corporais, compreendendo que eles são necessários, porém, insuficientes para garantir o desenvolvimento integral infantil, composto pelos aspectos motores, afetivos, sociais e cognitivos. Para isso, são necessários saberes que favoreçam a reflexão do seu fazer docente diante dos mais diversificados 
momentos da rotina diária da creche, possibilitando intervenções pedagógicas planejadas e mediadas intencionalmente, na busca pelo objetivo traçado pela instituição, as quais avancem quanto ao saber educativo do professor de creche.

Cremos que a formação inicial e/ou continuada necessita articular dois campos teóricos que representam a função do professor de Educação Infantil - o cuidado e a educação -, relacionando as especificidades desses aspectos no trabalho educativo a ser desenvolvido com os bebês.

Os adultos são responsáveis pela educação dos bebês, mas, para compreendê-los, é preciso estar com eles, observar, "escutar as suas vozes", acompanhar os seus corpos. O professor acolhe, sustenta e desafia as crianças para que elas participem de um percurso de vida compartilhado. Continuamente, o professor precisa observar e realizar intervenções, avaliar e adequar sua proposta às necessidades, desejos e potencialidades do grupo de crianças e de cada uma delas em particular (BARBOSA, 2010, p.6).

Assim, na tentativa de identificar e de elaborar um ensaio sobre os saberes necessários para a garantia da profissionalidade do professor que atua pedagogicamente com bebês, apresentaremos a seguir as principais ideias das produções selecionadas por meio do mapeamento bibliográfico realizado. Conforme Ferreira (2002), esse tipo de pesquisa é considerada

[...] de caráter bibliográfico, elas parecem trazer em comum o desafio de mapear e de discutir uma certa produção acadêmica em diferentes campos do conhecimento, tentando responder que aspectos e dimensões vêm sendo destacados e privilegiados em diferentes épocas e lugares, de que formas e em que condições têm sido produzidas certas dissertações de mestrado, teses de doutorado, publicações em periódicos e comunicações em anais de congressos e de seminários. Também são reconhecidas por realizarem uma metodologia de caráter inventariante e descritivo da produção acadêmica e científica sobre o tema que busca investigar, à luz de categorias e facetas que se caracterizam enquanto tais em cada trabalho e no conjunto deles, sob os quais o fenômeno passa a ser analisado (p. 258).

Entendemos que, dessa forma, poderemos, mesmo que dentro da faixa temporal limite estabelecida metodologicamente, destacar os contributos de diversos pesquisadores que se preocuparam com as práticas pedagógicas realizadas no interior das creches e, assim, colaborar para a consolidação de saberes os quais constituem da profissionalidade da professora atuante com bebês. 


\section{O QUE APONTAM AS PESQUISAS SOBRE OS SABERES E ELEMENTOS DA PROFISSIONALIDADE DOS PROFESSORES DE BEBÊS?}

O levantamento aqui realizado teve como objetivo principal destacar o que pesquisas recentes têm destacado como característica da função do professor atuante com bebês na creche. Acreditamos que o número de publicações encontradas esteja fortemente ligado às conquistas políticas alcançadas nessa etapa educacional. Em sua maioria, a produção é divulgada, sobretudo durante a ANPed, espaço de socialização de estudos e pesquisas. No entanto, em relação à quantidade de trabalhos que tratam da Educação Infantil, são poucos aqueles que abarcam o trabalho pedagógico com bebês e, quando nos voltamos especificamente para os saberes que constituem a profissionalidade dessa função, a quantidade de pesquisas demonstra-se ainda mais escassa.

Mesmo assim, acreditamos que as pesquisas encontradas podem trazer contributos que auxiliem na construção da profissionalidade da professora que atua com bebês. Desse modo, apresentamos a seguir as pesquisas que vão ao encontro do nosso objetivo, isto é, abordam saberes necessários para a garantia da profissionalidade do professor de bebês.

Um conjunto de pesquisadores tem evidenciado que a relação pedagógica estabelecida entre o bebê e o professor seja guiada pelos indícios externos que os bebês apresentam. Os autores pesquisados enfatizam que, em razão da ausência da fala como viés de comunicação dos bebês, os professores, ao atuarem na creche, precisam estar atentos aos indícios externos lançados pelos bebês e entendê-los como seres sociais, com potencialidades e ativos. Tais manifestações são marcos de seus níveis psíquicos e que, portanto, podem ser concebidos como guias da prática pedagógica. Tais ideias convocam um olhar atento e curioso para a criança, perpassado pela construção por parte da professora de uma sensibilidade com respeito à criança, tendo como perspectiva uma atitude investigativa na qual o adulto profissional busca compreender a ação infantil, perscrutando seus mecanismos sociais, afetivos e mentais. E mais: realça uma sensibilidade que é 
propalada pela observação atenta do comportamento interativo da criança, aliada à investigação da própria prática que desenvolve.

Para Guimarães (2006), os professores precisam apostar na construção da identidade educacional das creches, considerando a importância de tomar as crianças como ponto de partida. Para isso, basta observar e registrar suas iniciativas comunicacionais; por exemplo, as brincadeiras que inventam, a forma como se engajam na realidade circundante, a imitação (por iniciativa das próprias crianças) são indícios que revelam intensa disponibilidade para o contato, a troca e o aprender com o outro.

Em concordância, Ramos (2011) problematiza a histórica concepção que coloca o bebê numa posição de incompetência, subordinação e preparação para a vida adulta, bem como a necessidade de entendê-lo como capaz de tomar iniciativas e agir. O bebê dispõe de amplos recursos, desde seu nascimento, para interagir com e no mundo, em suas experiências, com outros sujeitos, sejam adultos, sejam parceiros de idade ou não, sendo capaz de agir/refletir sobre o que produz e o que vivencia culturalmente. Portanto, o trabalho de escuta e atenção às possibilidades expressivas da criança emerge como possibilidade para que a professora conheça os modos próprios de pensar e a versatilidade de ações sociocomunicativas que a criança empreende, para partilhar seus desejos, necessidades e intenções como elementos contextualizadores da organização didática.

Também nessa direção, Eltink (2000) procurou apresentar e discutir indícios (sinais, pistas) que crianças com menos de dois anos de idade ofereciam aos educadores de berçário, como suporte para a avaliação da adaptação na creche. Para essa educadora, identificar e compreender o que as crianças querem dizer com indícios como, por exemplo, o sorriso, o choro, dormir ou não dormir, agarrar na mãe, chamar pela mãe, reagir contra a aproximação da professora ou aceitar o seu colo, fugir dela ou aceitar sua aproximação, reações de protesto à separação dela ou busca de proximidade, reações de estranhamento a ela ou a sua ausência, entre outros, pode ajudar os educadores a refletir acerca do processo de adaptação dos bebês e das famílias à creche. A observação atenta desses indícios e o acompanhamento permanente dos mesmos possibilitam a elaboração e a assistência mais adequada do atendimento às necessidades e ao desenvolvimento em processo dos bebês. 
A proposta do trabalho de Guimarães (2008) foi discutir a qualidade das práticas de cuidado na creche e a perspectiva acerca dos bebês, nesse contexto. A pesquisa de campo em um berçário de uma creche pública evidenciou situações nas quais a disciplina e a instrução marcam as relações dos adultos com os bebês, e outros momentos em que, ao examinarem suas ações e emoções, os adultos abrem espaço para que eles sejam vistos de outra maneira, potentes, ativos, inventivos. A própria pesquisadora, ao acompanhar os bebês ao longo da pesquisa, por meio de registros fotográficos, observou como os bebês constituem sentidos no olhar, na imitação, oferta de objetos e outras diferentes formas de contato e troca com adultos e com outros bebês. A estudiosa finaliza seu trabalho, ressaltando que é preciso levar em conta a qualidade ética do cuidado, para além do atendimento às necessidades básicas das crianças. Sob essa afirmação, os educadores precisam envolver-se num trabalho sobre si mesmos, que coloque em questionamento seus modos de fazer, sentir, olhar e agir com as crianças.

Dagnoni (2012) buscou capturar o ponto de vista dos bebês, através de suas possibilidades expressivas não-verbais, suas intenções, interesses e necessidades, ao partilhar significados pelos meios funcionais de que dispõem, mesmo na ausência da fala articulada, em situações cotidianas da Educação Infantil. Tais ideias convocam um olhar atento e curioso para a criança, perpassado pela construção, por parte do(a) professor(a), de uma sensibilidade em relação à criança, tendo como perspectiva uma atitude investigativa em que o adulto profissional busca entender a ação infantil, perscrutando seus mecanismos sociais, afetivos e mentais. E mais: realça uma sensibilidade que é propalada pela observação atenta do comportamento interativo da criança, aliada à investigação da própria prática que desenvolve. Com base nesse olhar, a autora ressalta a concepção de educação, centrada na criança, que vem sendo pensada: aquela que enxerga e acolhe o protagonismo social infantil e que procura aprender com as crianças, conhecer seus gestos, ouvir suas falas, compreender suas interações como bússolas a indicar caminhos e traçar rotas a serem navegadas pela Educação Infantil. Essa concepção toma como pressupostos as ideias de que eles têm o que dizer, ou seja, possuem recursos sociocomunicativos para demonstrar, tendo essas informações como elemento balizador da organização das práticas educativas. 
Para que essa relação seja ainda mais próxima, alguns autores trazem para a discussão a afetividade. Essa temática apresentou-se como um tema recorrente, entre os pesquisadores dessa faixa etária. Lima (2013) procurou abranger a afetividade na formação e prática do professor de Educação Infantil, a partir do toque. A pesquisa foi realizada em uma instituição do interior paulista que atende a crianças de 4 meses a 5 anos, e contou com a participação de 22 professoras. Buscando trabalhar a shantala como estratégia de contato afetivo entre professoracriança, a pesquisadora considerou necessário compreender, pelas vivências e, posteriormente, por relatos, como as professoras percebiam a afetividade em sua vida pessoal e profissional, compreendendo suas concepções sobre esse aspecto do desenvolvimento infantil. As professoras experimentaram o contato e as manifestações promovidas por ele, para, posteriormente, colocá-lo em prática com os pequenos. O autor apresenta um episódio de mudança de atitude de uma professora de berçário, a qual havia relatado dificuldades para as trocas afetivas, realizando a massagem em um bebê com dificuldades para dormir. Cabe ressaltar que não consta na produção o detalhamento das atividades efetivadas com as professoras, as quais poderiam servir de aporte para o trabalho em sala de aula de outros profissionais. A pesquisadora relata o envolvimento dos professores na participação das atividades e mudanças nas práticas corporais direcionadas às crianças, no âmbito da sala dos agrupamentos. Pontua, também, que a afetividade é concebida pelos professores como amor e carinho - maior índice de respostas - e aponta a necessidade de haver, na formação inicial e continuada dos professores, conteúdos que considerem a dimensão afetiva, nesse caso, a epidérmica, como uma das linguagens infantis.

Por sua vez, Cacheffo (2012) se propôs investigar as concepções de afetividade - emoção, sentimento e paixão - de professoras de uma creche universitária, de modo a identificar como lidam com as manifestações afetivas das crianças, procurando dar visibilidade às práticas educativas que favoreçam o desenvolvimento infantil. A análise dos dados coletados, por meio de observações, entrevistas, pesquisa bibliográfica e análise documental, revelou que a concepção de afetividade dos professores é definida tomando como base as interações estabelecidas com as crianças, relação esta caracteristicamente afetiva que se traduz em respeito às especificidades da criança. No que concerne às práticas 
educativas, a pesquisadora constatou episódios que evidenciaram posturas e estratégias para lidar com as manifestações emocionais dos bebês e crianças pequenas, episódios em que as professoram agiam desconsiderando a razão e que as interações entre criança-criança, fundamentais para o desenvolvimento psicológico infantil, são permeadas constantemente pela mediação das professoras, realçando a necessidade do planejamento de situações que afetem positivamente as crianças. Em suas considerações finais, a pesquisadora salienta que, tendo por pressuposto que a afetividade se manifesta pela ativação provocada pelo outro, o papel dos profissionais que atuam com bebês e crianças é de fundamental importância, no que tange a significar as manifestações das crianças, pois, ao lidar com as manifestações de tonalidades desagradáveis que potencializam o surgimento de situações de angústia e ansiedade, as professoras podem diluir as manifestações prejudiciais ao desenvolvimento infantil e promover práticas educativas com tonalidades afetivas positivas. Para isso, é necessário conhecer o desenvolvimento infantil e suas especificidades e ter aparato teórico-metodológico para mediar as situações qualitativamente, afetando positivamente as crianças que estão sob sua responsabilidade.

Por sua vez, Birchal (2010) teve como objetivo investigar a exploração lúdica e a afetividade em crianças de zero e dois anos de idade, atendidas em berçários de creche sob o enfoque teórico piagetiano. A investigação, realizada sobretudo por meio de filmagens, e a teoria de Piaget levaram a pesquisadora a compreender a importância da afetividade como complementar à inteligência e como algo que afeta, positiva ou negativamente, o desenvolvimento da criança. Além disso, a pesquisa ainda mostra a importância da exploração lúdica dos objetos/brinquedos, para o desenvolvimento afetivo das crianças pequenas.

Para além da relação professor/bebê, Pantalena (2010) objetivou estudar as relações entre família, creche e criança, durante o período de ingresso da criança e família em uma instituição educacional. Mediante etnografia, entrevistas, questionários, observações, fotos, filmagem e leitura do projeto pedagógico de um centro de Educação Infantil, a pesquisadora identificou que a relação professoracriança não tinha intencionalidade pedagógica, pois acontecia em um plano intuitivo. Os bebês não eram "escutados" pelos choros, sorrisos, apatia e balbucios, as manifestações lúdicas dos bebês não eram valorizadas como momento de 
interação, a formação inicial e continuada não contemplava o estudo da formação dos vínculos. Ainda de acordo com Pantalena, faz-se necessário estabelecer relação entre professora, mãe e bebê, visando ao bem-estar e desenvolvimento emocional da criança, para o que é preciso conhecimento e habilidades específicas. É necessário acolher as expressões do bebê, para identificar as suas necessidades: dar voz à criança significa acolhê-la, compreendê-la. Interações nos momentos de ludicidade e exploração do ambiente contribuem para o bem-estar do bebê, favorecem a adaptação ao ambiente e a formação de vínculo afetivo entre professora/bebê. Existe escassez de produção científica sobre a temática, a qual precisa estar à disposição para a discussão.

Oliveira e Abramowicz (2005) abordaram questões voltadas para a infância, o espaço da creche e a temática racial, estruturando as práticas educativas, e a relação cotidiana entre adultos e crianças. Os dados coletados mostraram que havia certa comparação/classificação entre as crianças. A questão racial apareceu na relação das pajens com as crianças negras. Havia "paparicação" com determinadas crianças, baseando-se num todo social homogêneo em relação ao gênero, estereótipo de beleza, cor da pele. Para as autoras, a creche precisa assumir uma educação para a multidão, ou seja, que não tenha como prática a eliminação das diferenças, na qual as crianças encontram uma forma de ligação, de agenciamento, de sociabilidade; um espaço onde o familiar, o fraterno ceda lugar ao que é estranho, diferente ou diverso, a fim de que as crianças não se fechem ao desconhecido e só busquem o que é semelhante, o que gera identificação, ou seja, os "pares". É no espaço público, na relação com o outro que constituímos nossa subjetividade, nossas diferenças.

Outro contingente de pesquisas que buscam trazer contributos à área problematizou a questão da formação continuada e/ou em serviço, para avançar aos resquícios históricos instalados na identidade e, consequentemente, sobre os saberes dos professores responsáveis pelo trabalho com bebês. É unânime entre esses pesquisadores que são necessários momentos e investimentos para a formação continuada desses profissionais. As experiências demonstram o avanço identificado, independentemente do suporte teórico utilizado.

Kopcak (2009) buscou investigar como os conceitos teóricos sobre infância e trabalho com a Educação Infantil, elaborados pelas monitoras que participaram de 
um curso de aperfeiçoamento oportunizado pela Rede Municipal de Educação de Campinas, mediatizaram a identidade e a prática dessas profissionais. $\mathrm{O}$ curso visava a articular os conhecimentos práticos das monitoras de Educação Infantil com os saberes teóricos da área. As narrativas e entrevistas constituíram-se como instrumentos metodológicos e foram analisadas com base nos pressupostos de Bakhtin. A participação no curso permitiu que as monitoras constituíssem e compreendessem sua identidade profissional e refletissem sobre sua função profissional. A pesquisa revelou situações que ocorrem em diversos municípios de nosso país, como a presença de professor e monitor responsável pelo mesmo agrupamento, sendo que a função pedagógica fica sob a responsabilidade do professor, e o cuidado, no caso, de caráter higienista, é função dos monitores. Esse modo de organização pode motivar conflitos e oposições entre esses profissionais. Os dados examinados mostraram que as monitoras passaram a perceber-se como educadoras infantis responsáveis pela função educativa do cuidado. O curso de formação também promoveu acesso e sistematização dos conhecimentos teóricos sobre infância, com o intuito de propiciar que as monitoras pudessem refletir sobre as atividades propostas pelas professoras às crianças e, dessa forma, oferecer subsídios para participar das atividades educativas.

Em outra realidade, Souza (2012) realizou uma pesquisa com professores cursistas do Programa de Formação Inicial para Professores em exercício na Educação Infantil (PROINFANTIL), contratados pela Secretaria Municipal de Educação do município do Rio de Janeiro como Agentes Auxiliares de Creche, mas em exercício docente nas creches públicas municipais. A autora percebeu uma cisão entre creche e pré-escola, na qual a primeira instituição ocupa lugar muito mais frágil, equipamento destinado às crianças pobres e às classes populares, com profissionais sem habilitação para o trabalho. A identidade desses profissionais temse constituído culturalmente relacionada ao papel da mulher, da mãe, da faxineira, da dona de casa. Concluindo, Souza (2012) acredita que a formação como continuum favorece a construção da identidade desses profissionais, como também a produção de saberes. Por dois anos, os cursistas encontram-se sistematicamente para discutir o trabalho com as crianças, criando um território comum para pensar a formação e os saberes docentes. É no diálogo com os outros que esses educadores vão construindo saberes, ressignificando a prática. É na interação entre os saberes 
e as situações problemáticas do cotidiano que se dá a formação, de sorte que a experiência passa a ser entendida como espaço de desenvolvimento profissional e de produção de conhecimentos.

Borges (2009) investigou, em sua tese, a influência de um curso de extensão, com base na teoria piagetiana, na formação continuada de professoras que atuavam em creches. A pesquisa foi desenvolvida em três etapas, a saber: questionário demográfico e teste situacional; curso de extensão PROEPRE - "Fundamentos teóricos e práticas pedagógicas para a educação infantil I"; e teste situacional. Os dados obtidos foram analisados estatisticamente, com o intuito de apresentar e analisar as concepções teóricas das 63 professoras - sujeitos da pesquisa. Ainda segundo a autora, o curso propiciou mudanças nas concepções dos participantes constatação baseada nas análises das respostas do teste situacional aplicado no início e no final do curso, constatando que idade, tempo de serviço, formação inicial e carga horária de trabalho não influenciaram essa mudança. Pontuou-se, também, a relevância de cursos direcionados aos professores de creche, uma vez que indicaram, inicialmente, desconhecimento sobre as especificidades do desenvolvimento infantil de 0 a 3 anos, sobre os conteúdos e trabalho pedagógico a ser desenvolvido, o que retrata que a formação inicial das professoras é insuficiente quanto às disciplinas que abordem teorias e práticas pedagógicas referentes à Educação Infantil - creche e pré-escola.

Costa (2006) verificou se a participação dos educadores de creche, em um curso de formação continuada, promoveu mudanças nas práticas educativas realizadas com as crianças. $O$ curso teve duração de 10 meses e contou com a participação de 26 educadores de creches assistenciais. Com base na pesquisaação, foram disponibilizados subsídios teóricos piagetianos aos educadores, no que diz respeito ao desenvolvimento infantil - físico, afetivo, cognitivo e social -, e à construção do conhecimento com base no construtivismo. Além do curso, foram realizadas supervisões nos locais de trabalho dos educadores, com o objetivo de observar a estruturação do espaço físico, a relação educador-criança, a rotina e as atividades pedagógicas desenvolvidas. Foram coletados dados via teste situacional, e a análise quantitativa desse instrumento metodológico revelou mudanças nos posicionamentos das educadoras, assim como os dados coletados nas observações 
das supervisões permitiu constatar modificações nas práticas educativas efetivadas com as crianças.

Com um aporte teórico diferente, Silva (2008) buscou investigar se as ações educativas estão promovendo o cuidar e o educar, considerando a ligação imprescindível entre eles, para a promoção do desenvolvimento psicológico das crianças menores de três anos, à luz dos preceitos teóricos da Psicologia HistóricoCultural. A pesquisa de campo realizada nas instituições de Educação Infantil em questão possibilitou à pesquisadora constatar que o trabalho docente ainda está mais voltado para questões assistenciais do que educativas. A visão de ensino defendida pela pesquisadora, sob o aporte teórico anunciado, compreende o trabalho educativo como sendo 0 ato de produzir, direta e intencionalmente, em cada indivíduo singular, a humanidade que é produzida histórica e coletivamente pelo conjunto dos homens, sem, portanto, excluir o cuidar.

Cunha e Carvalho (2002) problematizam a discussão sobre a indissociabilidade do educar e o cuidar, em duas creches, uma filantrópica e outra pública. As pesquisadoras observaram que, na creche filantrópica, se revelava maior contato pessoal das monitoras com as crianças, sempre com muita rapidez, em decorrência do elevado número de crianças por adulto. Na creche pública, a alimentação e a higienização (banho, escovação, trocas de roupas etc.) eram feitas em recintos comuns às turmas, ocasionando uma oportunidade de encontro das diversas educadoras e, assim, havendo maior interação entre os adultos do que destes com as crianças. A despeito do grande número de crianças, a forma mais afetiva e maternal percebida nas monitoras da creche filantrópica em relação às educadoras da creche municipal, sugere que, para as primeiras, essas atividades são as que thes dão identidade, para as quais estão seguras de seu fazer; e fazer bem, na perspectiva dessas profissionais, é fazer com carinho e afeto. Por outro lado, para as educadoras da creche municipal - habilitadas para o magistério, em sua maioria - essas ações não são as que correspondem ao modelo idealizado de professoras. Notamos em ambas as creches, uma grande preocupação com a integridade física das crianças, justificando ações de contenção e de impedimento de exploração do ambiente. Entre todas as práticas, a que se referia ao sono das crianças mostrou-se a mais opressora e impositiva (como o uso de toalhas cobrindo o rosto, a contenção física ou medidas mais suaves, como músicas e embalos). A 
forma como o brincar é proposto e ocorre, nas creches pesquisadas, indica uma concepção de criança e de educação voltada para a necessidade prioritária de adaptação do sujeito ao meio, e não de desenvolvimento a ser realizado em um processo contínuo de interação entre a criança e o ambiente físico e social em que vive, incluindo aí os adultos e as outras crianças.

Ambrosetti e Almeida (2007), com o intuito de investigar a construção da profissionalidade dos professores de Educação Infantil e os elementos que compõem o processo de tornar-se professor, optaram pela abordagem qualitativa e pela técnica de grupo focal, concretizada com sete professoras. Os dados coletados foram organizados em unidades de análise: saberes e espaços na aprendizagem da docência; identificação com a profissão; concepções e sentimentos sobre a docência; e cotidiano do trabalho docente. Essa análise possibilitou a compreensão de que a profissionalidade se constitui em um processo dinâmico, composto pelas dimensões afetivas, cognitivas e sociais das professoras, e seu desenvolvimento se dá durante toda a carreira do magistério. Para as autoras,

[...] profissionalidade e profissionalização mantêm uma relação dialética, ou seja, o desenvolvimento da profissionalidade dos professores, que envolve os conhecimentos e habilidades necessários ao seu exercício profissional, está articulado a um processo de profissionalização, que requer a conquista de um espaço de autonomia favorável a essa constituição, socialmente reconhecido e valorizado (AMBROSETTI; ALMEIDA, 2007, p.3-4).

Roca (2012) pesquisou o processo de formação das professoras de Educação Infantil que atuam no Brasil e em Portugal, com o intuito de compreender o processo de profissionalização dos docentes. Valendo-se das narrativas das professoras, a autora procurou estabelecer comparações entre a formação e ação profissional dos professores do Rio de Janeiro (Brasil) e Aveiro (Portugal). A análise dos dados permitiu constatar críticas aos cursos de formação, tais como ênfase em teorias e distanciamento das práticas, com conteúdos que desconhecem as necessidades das crianças e pouco destaque aos aspectos lúdico e afetivo. Notouse que as professoras têm consciência das mudanças, no processo de educação das crianças, e tentam acompanhá-las, ampliando seus saberes e suas práticas, pois compreendem que sua profissão foi produzida nos cursos de graduação e nas práticas educativas desenvolvidas em suas atuações profissionais. Segundo a 
autora, não foi possível destacar diferenças marcantes entre o processo de formação e ação profissional dos professores do Brasil e de Portugal.

Rego e Pernambuco (2006) analisaram os focos de dificuldades apresentadas pelos professores de Educação Infantil que participaram de um curso de formação continuada de 120 horas. Os dados integram a pesquisa "O Perfil do Educador Infantil e os Principais Desafios na sua Formação". O curso foi proposto para 29 municípios do Rio Grande do Norte e buscou atingir 1.260 professores. O estudo apontou como desafios a serem superados, na formação e atuação profissional dos professores: função da creche e pré-escola, visão de infância, desenvolvimento infantil, cuidar e educar e conteúdos e metodologias para o trabalho com as crianças.

Dieb (2006) analisou como os professores de Educação Infantil compreendem a atividade que exercem, constroem seus saberes. Para a autora, as concepções estão no mesmo patamar das representações sociais, ou seja, "[...] forma de conhecimento, socialmente elaborada e partilhada, com um objetivo prático, e que contribui para a construção de uma realidade comum a um conjunto social" (JODELET, 2001, p. 22). Para a coleta dos dados, a autora utilizou-se do instrumento metodológico balanço do saber (CHARLOT, 2000). Com base na análise do balanço do saber de 26 professoras da rede municipal de Rio Grande do Norte, constatou-se que as professoras compreendem sua atuação como trabalho e não como vocação e que o caráter assistencialista deu lugar à dimensão pedagógica do trabalho docente. Verificou-se, ainda, que essas professoras sabem de que somente a prática não garante a formação e a profissionalização e que creditam à universidade e aos cursos de Pedagogia a construção dos conhecimentos para atuação na área.

Em sua pesquisa, Cota (2007) procurou verificar, por meio de estudos de História Oral, os possíveis traços e processos identitários de trabalhadoras de creches, constituídos na trajetória de vida e de trabalho de cinco mulheres/professoras. Pôde comprovar que foi grande a tensão instaurada entre 0 real e o idealizado, não só pelo que prevê a lei, como também pelo sentimento expresso pelas trabalhadoras de creche em relação ao seu trabalho. Nesse sentido, identificou possíveis traços identitários construídos e reconstruídos, ao longo de suas trajetórias de vida. O primeiro possível traço identificado foi a atitude maternal 
revelada na defesa pela paciência no trabalho com as crianças e pelo sentimento de amor por elas. Um segundo traço que se definiu foi a condição sociocultural e econômica das trabalhadoras, sendo todas de origem familiar de baixa renda e baixa escolarização, filhas de pais analfabetos, analfabetos funcionais ou apenas com o ensino primário. O terceiro marcador identitário, o qual se evidenciou foi a formação deficiente. Finalmente, foi possível perceber, diante dos significados expressos por elas, um sentimento de pertencimento a um grupo específico: sentem-se como "professoras de creche" e não como professoras da Educação Infantil. Os resultados demonstram, ainda, que o desejo de serem reconhecidas como professoras foi o que motivou o grupo a participar do Programa Emergencial, e também que há uma dificuldade instalada para se romper com a prática da assistência construída a partir da ênfase no cuidado.

Em contrapartida, Silva (2007) analisou as concepções que ancoram e/ou legitimam a atuação das professoras de creche. A pesquisa contou com a participação de seis profissionais, cinco das quais estavam em processo de formação. Por meio de entrevistas, constatou-se que a competência para o trabalho como educadora de creche se pauta nas habilidades pessoais, sobrepondo-se os elementos promovidos pela formação. Cabe salientar que apenas duas educadoras relataram o acesso à creche e à educação como direito da criança e desvalorização dos conhecimentos teóricos, em detrimento do saber-fazer.

Ao abordar o espaço como elemento central no trabalho com bebês, em uma creche pública municipal situada na região sul do Estado de Santa Catarina, Simiano e Vasques (2011) perceberam uma carência de mobiliários, equipamentos e brinquedos, para educar e cuidar de crianças pequenas. Em face de um espaço limitador, bebês e adultos transgrediram, subverteram a infraestrutura. Enquanto a professora e auxiliar se encontravam envolvidas nas ações pedagógicas de cuidado, os bebês transitavam livremente pela sala e, desfrutando de um tempo longe do olhar das educadoras, viveram outras relações além das estabelecidas com os adultos. Sendo os parceiros mais experientes do bebê e os organizadores do cotidiano, os adultos propiciaram contextos relacionais capazes de influenciar na sua trajetória de vida, para o posterior acúmulo de experiência. O espaço potencializa a educação. Contudo, é o olhar, a conversa, o toque, o sorriso, a brincadeira, as palavras, as relações e as experiências que constituem o espaço da creche, em um 
lugar para os bebês. Por isso, a importância de que o ambiente seja rico, diverso em materiais, brinquedo, mobiliário.

Abordando outra questão, Nascimento e Santos (2010) se propuseram questionar a preocupação e a intencionalidade para com a educação e o cuidado das crianças nos Centros de Educação Infantil (CEI) conveniados à Rede Municipal de Curitiba, no Paraná, sobre o teor das políticas públicas dos documentos internacionais, uma vez que norteiam políticas e práticas. O movimento histórico, no qual se inserem os CEls, indica que as tendências e orientações quanto à Educação Infantil, preconizadas nos documentos internacionais e no Brasil, estão sendo, paulatinamente, levadas em conta no planejamento e execução institucionais. Todavia, se há lampejos que desvendam avanços, as considerações das educadoras sobre as crianças e sobre sua prática com elas assinalam a permanência de certo cenário histórico que conjuga permanências e avanços, no atendimento infantil. Nessa perspectiva, práticas educativas e aspectos da formação inicial e em serviço dos educadores das crianças congregam elementos para que se continuem as discussões sobre a qualidade do atendimento, na Educação Infantil, em instituições como as creches comunitárias.

Sob a mesma preocupação, Bufalo (2009) discorre, em sua tese, como é constituída a profissão docente de creche, a partir das lutas e reivindicações dos movimentos de resistências culturais. Examina a formação docente no âmbito político, com base nos dados presentes nas atas e documentos do período de 1988 a 2001, disponibilizados pelo Sindicato dos Trabalhadores no Serviço Público Municipal de Campinas, além de três revistas da área de educação e um caderno de poesias que pertenciam à pesquisadora. Concebe as docentes de creche como uma profissão relacionada ao gênero feminino, pautada em uma pedagogia com três atores - criança, família e docente -, tendo por função o cuidar e o educar, os quais ocorrem nas relações entre professor-criança, elegendo como atributo especial o brincar.

Nas análises documentais e bibliográficas, Bufalo (2009) pontua que a profissão de docente de creche está sendo construída e que esta se baseia na práxis e não no praticismo. Aponta, ainda, que o docente de creche também se constitui nas lutas sindicais que promovem nesse trabalhador uma formação políticopedagógica, sendo o movimento sindical promotor de formação - garantindo a 
profissionalização docente - que inclui a profissionalidade. Finaliza, destacando que os professores de creches estão conscientes de suas funções, atribuições e limitações, e que reivindicam aspectos que extrapolam a valorização salarial, como, por exemplo, o investimento na formação docente.

\section{CONCLUSÕES}

A metodologia de pesquisa relatada neste artigo nos possibilitou o contato direto com diferentes estudos que se lançaram sobre as práticas pedagógicas realizadas com bebês. Foram identificadas diferentes abordagens teóricas utilizadas em diversos locais e sujeitos. Desses estudos, emergiram discussões que compreendemos contribuir para o avanço dos resquícios históricos, os quais colocam a função social da professora de creche no patamar de "mãe substituta/temporária". A fim de elaborarmos um ensaio teórico, procuramos evidenciar, nessas discussões, aspectos que entendemos cooperar com a profissionalidade da professora de bebês.

Como ressaltado ao longo deste estudo, os saberes educativos constituintes do professor que trabalha com bebês, nas creches brasileiras, perpassam diversas esferas. As pesquisas destacam a organização e implementação de processos de formação continuada e/ou em serviço, a garantia da função da Educação Infantil cuidar e educar -, a relação afetiva e lúdica entre o bebê e o professor, a sensibilidade no sentido de ver, "escutar" o bebê, dentro de suas possibilidades de comunicação, para que, por meio de suas manifestações, decorrentes de seu nível de desenvolvimento, a proposta seja feita com o intuito de lançá-lo em seu desenvolvimento.

Para isso, também podemos resgatar a discussão acerca do espaço como outro elemento educativo. O berçário, nessa visão, deixa de ser um mero espaço físico, sem vida, e passa a integrar as propostas educativas da instituição. Esses elementos combinados favorecem a adaptação do bebê e da mãe à creche. $A$ adaptação planejada, tomando como base as necessidades do bebê e da mãe, com um espaço preparado para dar voz aos pequenos, faz com que esse momento seja suave a todos os envolvidos. 
As pesquisas revelam igualmente para a necessidade de envolvimento com 0 processo de formação continuada dos professores. As experiências relatadas pelos autores demonstram mudanças qualitativas nas concepções e nas práticas dos docentes envolvidos, independentemente do aporte teórico adotado. Não podemos esquecer as pesquisas que apontam para a necessidade e a importância de envolvimento e engajamento político com as questões da creche.

Nessa perspectiva, é preciso avançarmos o campo de atuação das professoras de bebês, tendo clara a sua atuação pedagógica como qualitativamente diferenciada da vida cotidiana e da maternagem. As pesquisas aqui apresentadas revelam que esse fazer docente envolve conhecimentos científicos, filosóficos, sociológicos, os quais precisam ser lançados de forma que orientem o atendimento, a alimentação, o banho, o trato cotidiano, o toque e até mesmo o olhar entre o bebê e o professor.

A professora de bebês necessita de saberes específicos e, entre eles, destacamos: clareza e posicionamento em relação às concepções de criança e infância; conhecimentos científicos e teóricos sobre o desenvolvimento infantil e suas especificidades; compreensão da função de cuidar e educar, no planejamento de atos pedagógicos; capacidade de ensinar, ou seja, fazer aprender e ter reflexividade, isto é,

[...] capacidade de voltar sobre si mesmo, sobre as construções sociais, sobre as intenções, representações e estratégias de intervenção. [...] para enriquecer e modificar não somente a realidade e suas representações, mas também a próprias intenções e o próprio processo de conhecer. (PÉREZ GÓMEZ, 1998, p. 29)

Por fim, estamos conscientes da limitação desta pesquisa e de que não é possível definir os saberes inerentes e necessários do profissional que atua com bebês em apenas um momento histórico, mesmo que este os busque em outros trabalhos elaborados em outros tempos. Acreditamos, contudo, que os indicativos, aqui reunidos por meio de pesquisas já efetivadas, podem contribuir para a consolidação de saberes mínimos que não podem mais ser negados nas rotinas diárias, haja vista a cientificidade dos trabalhos mapeados.

\section{JOSÉ RICARDO SILVA}


Doutorando em Educação pela Universidade Estadual Paulista Júlio de Mesquita Filho (UNESP), Campus de Presidente Prudente - SP. Autor do artigo:

\section{VIVIANE APARECIDA FERREIRA FAVARETO CACHEFFO}

Professora Mestre em Educação (2012) pela, doutoranda em Educação pela FCT/Unesp, bolsista Capes.

\section{CÉLIA MARIA GUIMARÃES}

Possui Pós-Doutorado pela Universidade de Lisboa-Portugal e pela Escola Superior de Educação do Instituto Politécnico de Santarém-PT.

\section{REFERÊNCIAS}

AMBROSETTI, N. B.; ALMEIDA, P. A. de. A constituição da profissionalidade docente: tornar-se professora de educação infantil. In: REUNIÃO ANUAL DA ANPED, 30, 2007, Caxambu. Anais. Caxambu: Anped, 2007. p.1-16. Disponível em: $<$ http://30reuniao.anped.org.br/trabalhos/GT08-3027--Int.pdf>. Acesso em: 15 jun. 2014.

ÁVILA, M. J. F. As professoras de crianças pequeninas e o cuidar e educar. In: REUNIÃO DA ASSOCIAÇÃO NACIONAL DE PÓS-GRADUAÇÃO E PESQUISA EM EDUCAÇÃO, 25., 2002, Caxambu. Anais... Caxambu: Anped, 2002. p. 1-16. Disponível em: <http://www.anped.org.br/reunioes/25/mariajoseavilat07.rtf>. Acesso em: 09 jun. 2010.

BARBOSA, M. C. Especificidades da ação pedagógica com os bebês. In: Programa Currículo em Movimento. 2010. Disponível em:

http://portal.mec.gov.br/index.php? Itemid=1096\&id=15860\&option=com_content\&vie $\mathrm{w}=$ article. Acesso em: 05 dez. 2010.

BIRCHAL, P. S. Exploração lúdica e afetividade em crianças de creche. 2010. 204p. Tese (Doutorado) - Instituto de Psicologia da Universidade de São Paulo, São Paulo.

BORGES, R. R. Curso de Extensão Universitária PROEPRE: contribuição para a formação de professores de creche. 2009. 327 p. Tese (Doutorado) - Universidade Estadual de Campinas, Campinas.

BUFALO, J. M. P. Nem só de salário vivem as docentes de creche: em foco as lutas do Sindicato dos Trabalhadores no Serviço Público Municipal de Campinas (STMC 1988-2001). 2009. 179 p. Tese (Doutorado) - Universidade Estadual de Campinas, Campinas.

CACHEFFO, V. A. F. F. Manifestações afetivas nas concepções e práticas educativas no contexto da creche: reflexões a partir da perspectiva walloniana. 2012, 115p. Dissertação (Mestrado) - Universidade Estadual Paulista, Faculdade de Ciências e Tecnologia - Presidente Prudente. 
CAMPOS, M. M. A educação infantil frente aos seus desafios. Difusão de Ideias, São Paulo, Fundação Carlos Chagas, p. 01-14, mai.2009.

CERISARA, A. B. Educar e cuidar: por onde anda a educação infantil? Perspectiva, Florianópolis, v. 17, n. especial, p. 11-21, jul./dez. 1999. Disponível em: <http://www.periodicos.ufsc.br/index.php/perspectiva/article/viewFile/10539/10082>. Acesso em: 05. jun. 2010a.

CERISARA, A. B. O referencial curricular nacional para a educação infantil no contexto das reformas. Educação e Sociedade, Campinas, v. 23, n. 80, p. 326-34, set. 2002. Disponível em: <http://www.scielo.br/pdf/es/v23n80/12935.pdf>. Acesso em: 05 jun. $2010 b$.

CHARLOT, B. Da relação com o saber: elementos para uma teoria. Tradução de Bruno Magne. Porto Alegre: Artes Médicas, 2000.

COSTA, D. P. L. P. A influência de um programa de formação continuada no desempenho de profissionais de creches assistenciais com vistas à implantação do Proepre. 2006. 167 p. Dissertação (Mestrado) - Universidade Estadual de Campinas, Campinas.

COTA T. C. M. "A gente é muita coisa para uma pessoa só": desvendando identidades de "professoras" de creches. REUNIÃO ANUAL DA ANPED, 30. Anais... Caxambu, 2007 Disponível em: http:<//30reuniao.anped.org.br/trabalhos/GT07-3129-Int.pdf.> Acesso em: 15 mai. 2014.

CUNHA B. B. B.; CARVALHO, L. F. Cuidar de crianças em creches: os conflitos e os desafios de uma profissão em construção. In: REUNIÃO ANUAL DA ANPED, 25. Anais...Caxambu, 2002 Disponível em: http:<//25reuniao.anped.org.br/beatrizbrandocunhat07.rtf.> Acesso em: 16 maio 2014.

DAGNONI A. P. R. Quais as fontes de saberes das professoras de bebês? In: REUNIÃO ANUAL DA ANPED, 35. Anais... Porto de Galinhas, 2012. Disponível em: $<$ http://35reuniao.anped.org.br/images/stories/trabalhos/GT07\%20Trabalhos/GT071910_int.pdf> Acesso em: 02 maio 2014.

DIEB, M. Educação infantil: espaço de representações sociais e de relações com o saber. In: REUNIÃO ANUAL DA ANPED, 29. Anais... Caxambu, 2006. p.1-13. Disponível em: <http://29reuniao.anped.org.br/trabalhos/trabalho/GT08-1774-Int.pdf>. Acesso em: 15 jun. 2014.

ELTINK C. F. Indícios utilizados por educadores para avaliar o processo de inserção de bebês em uma creche. In: REUNIÃO ANUAL DA ANPED, 23. Anais... Caxambu, 2000. Disponível em: <http://23reuniao.anped.org.br/textos/0709t.PDF>. Acesso em: 15 mai. 2014.

FERREIRA, N. S. de A. As pesquisas denominadas "estado da arte". Educação \& Sociedade, Campinas, ano XXIII, n. 79, p. 257-272, ago. 2002. 
GATTI, B. Formação de professores e carreira. São Paulo: Cortez, 1997.

GUIMARÃES, D. O. Entre a instrução e o diálogo: a construção da identidade educacional das creches. In: REUNIÃO ANUAL DA ANPED, 29. Anais... Caxambu, 2006 Disponível em: <http://29reuniao.anped.org.br/trabalhos/trabalho/GT07-2328-Int.pdf>. Acesso em: 15 mai. 2014.

GUIMARÃES, D. O. No contexto da creche, o cuidado como ética e a potência dos bebês. In: REUNIÃO ANUAL DA ANPED, 31. Anais... Caxambu, 2008. Disponível em: <http://31reuniao.anped.org.br/1trabalho/GT07-4807--Int.pdf>. Acesso em: 15 mai. 2014.

JODELET, D. Representações sociais: um domínio em expansão. In: JODELET, D. (Org.). As representações sociais. Rio de Janeiro: Ed. UERJ, 2001. p.17-44.

KRAMER, S. Formação de profissionais de educação infantil: questões e tensões. In: MACHADO, M. L. A. Encontros e desencontros em educação infantil. São Paulo: Cortez, 2002. p.117 -326.

KOPCAK, S. C. P. No encontro, os sentidos: efeitos da formação de monitores de Educação Infantil. 2009. 224 p. Dissertação (Mestrado) - Universidade Estadual de Campinas, Campinas.

KUHLMANN JR., M. Educação Infantil e currículo. In: FARIA, A. L. G. de; PALHARES, M. S. (Orgs.). Educação Infantil pós-LDB: rumos e desafios. 5. ed. Campinas: Autores Associados, 2005.

KUHLMANN JR., M. Infância e Educação Infantil: uma abordagem histórica. 4. ed. Porto Alegre: Mediação, 2007.

LIMA, M. P. "VITÓRIA VAI À ESCOLA: o papel da afetividade na formação de professores da educação infantil". 2013. 164 p. Dissertação (Mestrado) Universidade Estadual de Campinas, Campinas.

LÜDKE M.; BOING, L. A. Caminhos da profissão e da profissionalidade docentes. Educ. Soc., Campinas, v. 25, n. 89, p. 1159-1180, set./dez. 2004. Disponível em: <http://www.scielo.br/pdf/es/v25n89/22616>. Acesso em: 17 fev. 2015.

MARTINS, L. M. O ensino e o desenvolvimento da criança de zero a três anos. In: ARCE, A.; MARTINS, L. M. Ensinando aos pequenos: de zero a três anos. Campinas: Alínea, 2009.

NASCIMENTO, E. R.; SANTOS A. V. dos. Cuidado ou educação? A prática educativa nas creches comunitárias de Curitiba. In: REUNIÃO ANUAL DA ANPED, 33. Anais... Caxambu, 2010. Disponível em:

<http://33reuniao.anped.org.br/33encontro/app/webroot/files/file/Trabalhos\%20em\%2 OPDF/GT07-6838--Int.pdf>. Acesso em: 15 mai. 2014. 
NOSELLA, P. A linha vermelha do planeta infância: o socialismo e a educação da criança. In: FREITAS, M. C.; KUHLMANN JR., M. (Orgs.). Os intelectuais na história da infância. São Paulo: Cortez, 2002. p. 129-165.

OLIVEIRA, F. de; ABRAMOWICZ, A. A "paparicação" na creche enquanto uma prática que inviabiliza a construção de uma educação da 'multidão'. In: REUNIÃO ANUAL DA ANPED, 28. Anais... Caxambu, 2005. Disponível em: <http://28reuniao.anped.org.br/gt07.htm>. Acesso em: 15 mai. 2014.

PANTALENA, E. S. O ingresso da criança na creche e os vínculos iniciais. 2010. 128 p. Dissertação (Mestrado) - Faculdade de Educação da Universidade de São Paulo, São Paulo.

PÉREZ GÓMEZ, A. I. A função e formação do professor/a no ensino para a compreensão: diferentes perspectivas. In: GIMENO SACRISTÁN, J.; PÉREZ GÓMEZ, A.I. Compreender e transformar o ensino. Porto Alegre: Artmed, 1998.

RAMOS T. K. G. Possibilidades de organização de práticas educativas na creche em parceria com os bebês: o que "dizem" as crianças? In: REUNIÃO ANUAL DA ANPED, 34. Anais... Natal, 2011. Disponível em: <http://34reuniao.anped.org.br/images/trabalhos/GT07/GT07-1092\%20int.pdf>. Acesso em: 14 maio 2014.

REGO, M. C. F. D.; PERNAMBUCO, M. M. C. A. Formação do educador infantil: identificando dificuldades e desafios. In: REUNIÃO ANUAL DA ANPED, 29. Anais... Caxambu, 2006. p.1-15. Disponível em: <http://27reuniao.anped.org.br/gt08/t0814.pdf>. Acesso em: 15 jun. 2014.

ROCA, E. C. L. A formação do professor de educação infantil: interfaces lusobrasileiras. In: REUNIÃO ANUAL DA ANPED, 35. Anais... Caxambu, 2012. p.1-17. Disponível em: <http://www.35reuniao.anped.org.br/trabalhos/108-trabalhos-gt08formacao-de-professores>. Acesso em: 15 jun. 2014.

ROLDÃO M. do C. Profissionalidade docente em análise - especificidades dos ensinos superior e não superior. Revista Nuances: estudos sobre educação - ano XI, v. 12, n. 13, p. 105-126, jan./dez. 2005.

SACRISTÁN, J. G.. Consciência e acção sobre a prática como libertação profissional dos professores. In: NÒVOA, A. (org.). Profissão professor. Portugal: Porto, 1991.

SANTOS, M. O. V. A identidade da profissional de educação infantil. In: GUIMARÃES, C. M. (Org.). Perspectivas para educação infantil. Araraquara: Junqueria \& Marin, 2005. p. 87-101.

SAYÃO, D. T. Não basta ser mulher... não basta gostar de crianças... "Cuidado/educação" como princípio indissociável na Educação Infantil. Educação, Santa Maria, v. 35, n. 1, p. 69-84, jan./abr. 2010. Disponível em: <http://www.ufsm.br/revistaeducacao. Acessado em: 01 de mai. de 2010. 
SILVA, I. O. Trabalho docente na educação infantil: dilemas e tensões. In: REUNIÃO ANUAL DA ANPED, 30. Anais... Caxambu, 2007. p.1-18. Disponível em:

<http://30reuniao.anped.org.br/trabalhos/GT08-3509--Int.pdf>. Acesso em: 15 jun. 2014.

SILVA, J. C. Práticas Educativas: a relação entre cuidar e educar e a promoção do desenvolvimento infantil à luz da Psicologia Histórico-Cultural. 2008. 214 p.

Dissertação (Mestrado) - Universidade Estadual Paulista, Faculdade de Ciências e Letras, Campus de Araraquara, Araraquara.

SIMIANO L. P.; VASQUES C. K. Sobre importâncias, medidas e encantamentos: o percurso constitutivo do espaço da creche em um lugar para os bebês. In: REUNIÃO ANUAL DA ANPED, 34. Anais... Natal, 2011. Disponível em:

<http://34reuniao.anped.org.br/images/trabalhos/GT07/GT07-410\%20int.pdf>. Acesso em: 14 mai. 2014.

SOUZA M. P. C. O proinfantil e a formação dos agentes auxiliares de creche do município do Rio de Janeiro. In: REUNIÃO ANUAL DA ANPED, 35. Anais... Porto de Galinhas, 2012. Disponível em:

http://35reuniao.anped.org.br/images/stories/trabalhos/GT07\%20Trabalhos/GT071895_int.pdf>. Acesso em: 02 mai. 2014. 